\title{
PROFORMA BILLANÇO HAZIRLAMA YÖNTEMLERİ ÜZERİNE BİR İNCELEME
}

\section{AN ANALYSIS OF PROFORMA BALANCE SHEET PREPARATION METHODS}

\author{
M. Altan MASUN* \\ Aclan OMA $\breve{G}^{\dagger}$
}

\begin{abstract}
Özet
İşletmeler, geleceğe dönük faaliyetlerini finansal planlama yardımıyla şekillendirir. Proforma bilanço, finansal yönetim fonksiyonları arasında yer alan finansal planlamanın önemli uygulamalarından bir tanesidir. Bunun nedeni, proforma bilanço yardımıyla gelecek dönemdeki kaynak ihtiyacı ya da fazlasının bugünden belirlenebilmesidir. Bu sayede, işletmeler daha sağlıklı finansal kararlar alabilirler. Proforma bilançonun, belirli bir tarih itibariyle düzenlenen klasik bilançodan farkı, geleceğe dönük ve isteğe bağlı olmasıdır. Proforma bilanço oluşturulurken çeşitli yöntemlerden yararlanılabilir. Bu yöntemler sırasıyla, kapsamlı bütçeleme yöntemi, satışların yüzdesi yöntemi, oranlar yöntemi, regresyon yöntemi ve günlük satışlar yöntemi olarak ifade edilebilir. Bu çalışmada, küçük ölçekli imalat sektöründe yeni kurulan örnek bir firmanın gelecek dönem proforma bilançosu oranlar yöntemiyle oluşturulmuştur. Bunun sebebi, söz konusu yöntemin hesaplamadaki kolaylığı ile yeni faaliyete geçen işletmelere uygulanabilirliği gibi üstünlükleridir. Elde edilen sonuçlara göre, yeni kurulacak örnek işletmenin gelecek yıl kaynak ihtiyacının bulunduğu görülmüştür. Kaynak ihtiyacı eklendiğinde, proforma bilançoda aktif ve pasif eşitliğine ulaşılmaktadır. Kaynak ihtiyacı karşılanırken, finansman politikası kapsamında, yabancı kaynaklar ya da özkaynaklardan yararlanılabilecektir.
\end{abstract}

Anahtar kelimeler: Finansal planlama, proforma bilanço, oranlar yöntemi

JEL Sinıflaması: G30, G32, G39

\begin{abstract}
Companies design their future operations with the help of financial planning. Proforma balance sheet is a fundamental tool of financial planning, which is among the functions of financial management. The main reason for this is that proforma balance sheet helps to determine the need for future financing or the availability of extra funds from today. Consequently, companies could make their financing, long-term investment, short-term investment and dividend decisions appropriately. Proforma balance sheet differs from the regular balance sheet as it is related to the future and discretionary. There are various methods which could be used in preparing proforma balance sheets. The most wellknown methods are comprehensive budgeting method, percentage of sales method, ratios method, regression method and daily sales method. In this study, the proforma balance sheet of a newly established company in the small-scale manufacturing sector is prepared with the help of the ratios method. The reasons for this are the easiness of the method and its suitability in the preparation of proforma balance sheets for newly established companies. Since, accounting data are not available for them, they could only prefer this method in preparing their proforma balance sheets. The results of this study suggest that the newly established firm is going to need extra funds next year because total assets are greater than total liabilities. The difference between total assets and total liabilities shows the amount of extra funds, which is necessary to make the proforma balance sheet properly. Extra funds could either be obtained from external resources such as debt or internal resources like equity.
\end{abstract}

Keywords: Financial planning, proforma balance sheet, ratios method

JEL Classification: G30, G32, G39

\footnotetext{
${ }^{*}$ Dr. Öğr.Üyesi, Marmara Üniversitesi, İşletme Fakültesi, İşletme Bölümü, masun@marmara.edu.tr ${ }^{\dagger}$ Doç.Dr., Marmara Üniversitesi, Bankacılık ve Sigortacılık Yüksekokulu, Sermaye Piyasası Bölümü, aomag@marmara.edu.tr
} 


\title{
1. GİRIŞ
}

İşletmeler faaliyetleri devam ederken gelecekle ilgili sürekli karar almak durumundadırlar. Bu kararları alırlarken geleceğin muhtemel risklerine karşı bugünden çeşitli önlemleri düşünmeleri gerekmektedir. Bu kapsamda, işletmelerin kullanabilecekleri araçlardan birisi de finansal planlamadır. Finansal planlama, finansal amaçlar için bir ön koşuldur (Ross vd. 2006: 91). Bu çerçevede, “...geleceğe yönelik hareket biçimini belirlemeye, politikaları saptamaya ve gözden geçirmeye katkıda bulunan bir finans tekniğgi” olarak tanımlanır (Uzun vd., 2003: 63). Proforma bilanço ise, finansal planlama kapsamında hazırlanan finansal planların bir unsurudur (Ceylan ve Korkmaz, 2017:115, 116).

Bu çalışma dört bölümden oluşmaktadır. Birinci bölümde proforma bilançonun hazırlanması ile ilgili genel bilgi verilmektedir. İkinci bölümde proforma bilanço hazırlanmasında kullanılan yöntemler ele alınmaktadır. Üçüncü bölümde proforma bilanço yöntemlerinden oranlar yöntemi küçük ölçekli imalat sektöründe yeni kurulacak bir firmaya uygulanmakta ve gelecek dönem kaynak ihtiyacı olup olmadığı belirlenmektedir. Son olarak, literatür ve elde edilen sonuçlar kapsamında proforma bilançoların işletmeler için önemi vurgulanmaktadır.

\section{PROFORMA BİLANÇONUN HAZIRLANMASI}

\subsection{Genel Açıklama}

Proforma bilanço, adından anlaşılacağı gibi bilançonun özel bir çeşididir. Proforma bilançoyu açıklamak için öncelikli olarak proforma kavramının nereden ortaya çıktığına bakmak gerekir.

Proforma kelimesine bakıldığında Latin kökenli olduğu görülmektedir. Ayrıca, bir şeyin değerinin bugünden belirlenmesi anlamındadır (Business Forecasting, 2018:1).

Proforma bilançoların, firmaya ilişkin bilgiler yardımıyla dönem sonu tahmini bilanço kalemlerinin değerlerinin hesaplanmasını sağladığı ifade edilmektedir. Bu sayede, ileride belirli bir tarihte aktif ve pasifin durumu gözlemlenerek kaynak eksikliği ya da fazlalığıyla karşılaşma olasılığı şimdiden belirlenmiş olur (Ceylan ve Korkmaz, 2017: 115,116).

Proforma bilançonun da bulunduğu proforma mali tabloların kredi işlemlerinde çeşitli işlevleri bulunmaktadır. İlk işlevleri, borçların geri ödenme olasılığını göstermeleridir. Bunu yaparken, iki değişkenden yararlanıldığı vurgulanmaktadır. Bunlar, borç alanın mali yapısı ile geri ödeme gücüdür. İkinci işlevi ise, kredi işlemlerinde zorunlu teminatların tutarının ve niteliğinin anlaşılmasıdır (Ruland ve Zhou, 2004: 34).

Proforma bilançoların, normal bilançolar gibi sürekli açıklanmadığı ifade edilmektedir. Bununla beraber, bazı mali tablo değişkenleri için tahminlerin büyük işletmelerin raporlarından elde edilebildiği vurgulanmaktadır. Bu kalemlere örnek olarak satışlar ve karlar gösterilebilir (Atrill, 2017:73).

\subsection{Proforma Bilanço Hazırlanmasında Kullanılan Belirli Yöntemler}

Proforma bilanço hazırlanmasında dört temel yöntem bulunmaktadır. Bunlar, kapsamlı bütçeleme yöntemi, satışların yüzdesi yöntemi, oranlar yöntemi ve regresyon yöntemidir.

\subsubsection{Kapsamlı Bütçeleme Yöntemi}

Tahmini bilançolar oluşturulurken, çeşitli yöntemler izlenebilir. Bu yöntemlerden kapsamlı bütçeleme detaylı bir yöntemdir. Söz konusu yöntemin aşamaları aşağıda belirtilmektedir (Gürsoy, 2014: 140).

\author{
-“Satış projeksiyonlarının yapılması \\ -Üretim miktarlarl ve maliyetlerin bütçelenmesi \\ -Satış, yönetim ve finansman giderlerinin bütçelenmesi \\ -Proforma gelir tablosunun belirlenmesi \\ -Duran varlık yatırımlarının bütçelenmesi \\ -Nakit bütçesinin düzenlenmesi \\ -Proforma bilançonun düzenlenmesi",
}


İlk olarak, satış projeksiyonu için satış fiyatı ve satış miktarı bilgilerinden yararlanıldığı görülmektedir. Daha sonra, proforma gelir tablosu için ikinci ve üçüncü aşamalar tamamlanmalıdır. Bu çerçevede, üretim planı, direkt ilk madde ve malzeme, direkt işçilik ve genel üretim giderleri gibi kalemlerin satışların maliyeti ile brüt karı belirlediği ifade edilmektedir. Proforma gelir tablosunda brüt kar sonrasındaki diğer gider unsurları da gelecek dönem için tahmini kar/zararı tespit etmektedir (Block vd., 2014:98).

Uzun vadeli satış tahminleri kapsamında planlanan duran varlık yatırımları için de yatırım bütçesinin oluşturulduğu belirtilmektedir. Bu sayede, proforma bilançoda duran varlık kaleminin tespit edilmesi kolaylaşır (Gürsoy, 2014: 146, 148).

Kapsamlı bütçelemede proforma gelir tablosu, tahakkuk esasına dayalıdır. Yani, para hareketlerini göstermez. $\mathrm{Bu}$ nedenle, gelecekteki nakit hareketlerinin izlenebilmesine yönelik olarak nakit bütçelerinden yararlanıldığı ifade edilmektedir (Block vd., 2014:102). Yeni faaliyete başlamış, borç miktarı fazla olan firmalar gibi belirli özellikleri olan firmalar bakımından daha önemli kabul edilen nakit bütçesinin fon kaynaklarının bulunması ve geri ödemelerle ilgili katkısının büyük olduğu vurgulanmaktadır (Tennent, 2013:217).

$\mathrm{Bu}$ süreç sonunda, proforma bilançolar yer almaktadır. Proforma bilançonun oluşturulması için yukarıda açıklanan proforma gelir tablosu, nakit bütçesi ve çeşitli öngörülerden yararlanılmaktadır (Kılıç, 2012: 213-215). Burada anlatılan yöntem Şekil 1'de görülmektedir.

Şekil 1: Kapsamlı Bütçeleme Yöntemi Aşamaları

\begin{tabular}{|c|c|c|c|}
\hline \multicolumn{4}{|l|}{ Satış Bütçesi } \\
\hline \multicolumn{4}{|l|}{ Üretim Bütçesi } \\
\hline $\begin{array}{l}\text { Direkt İlk Madde ve Malzeme } \\
\text { Bütçesi }\end{array}$ & $\begin{array}{ll}\text { Direkt } & \text { İşçilik } \\
\text { Bütçesi } & \\
\end{array}$ & $\begin{array}{l}\text { Genel } \\
\text { Giderleri Bütçesi }\end{array}$ & Üretim \\
\hline \multicolumn{3}{|l|}{$\begin{array}{l}\text { Satış } \\
\text { Giderleri Bütçesi }\end{array}$} & Yönetim \\
\hline \multicolumn{4}{|l|}{ Bütçelenmiş Gelir Tablosu } \\
\hline $\begin{array}{l}\text { Sermaye } \\
\text { Bütçesi } \rightarrow\end{array}$ & $\begin{array}{l}\text { Nakit } \\
\text { Bütçesi } \rightarrow\end{array}$ & $\begin{array}{l}\text { Bütçelenmiş } \\
\text { Bilanço }\end{array}$ & \\
\hline
\end{tabular}

Kaynak: Jerry J. Weygandt, Paul D. Kimmel ve Donald. E. Kieso (2016). Accounting Principles. Twelfth Edition. USA: John Wiley and Sons, s. 797.

\subsubsection{Satışların Yüzdesi Yöntemi}

İkinci yöntem ise satışların yüzdesi yöntemidir. Satışların yüzdesi yöntemi, "hesapların bir firmanın tahmin edilen satış düzeyine göre değiştirildiği bir finansal planlama yöntemi”’ şeklinde tanımlanır (Ross vd. 2006: 97).

Satışların yüzdesi yönteminin dört aşamalı olduğu görülmektedir. İlk aşamada, satışlarla bağlantılı bilanço kalemlerinin mevcut dönem satışlarına oranlandığı belirtilmektedir. Bu kapsamda, ilgili kalemlerin yıllık satışların yüzdesi cinsinden ifade edilebildiği vurgulanmaktadır. Dönen varlıklar, net maddi duran varlıklar ile kısa vadeli borçların bu kalemleri temsil ettiği görülmektedir. Duran varlıkların bu kalemler arasında ayırt edici bir niteliği bulunmaktadır. $\mathrm{Bu}$ çerçevede, ilgili kalemin satışlarla bağlantısının üretim kapasitesindeki artışa dayandığ vurgulanmaktadır (Aydın, Başar ve Coşkun, 2010:173). Tablo 1'de bu kalemler görülebilir. Buna karş1, özsermaye ile uzun vadeli borçlar için yatırım programı belirleyicidir. Yine özsermaye grubunda bulunan yedek akçelerin kar dağıtım politikasının yansıması olduğu belirtilmektedir. Bu nedenle, satışlarla bağlantısı doğrusal değildir. Yedek 
akçeleri artıran faktörler iki tanedir. Bunlar, işletme karlılığı ile dağıtılmayan karların miktarıdır (Keown vd.,2014:465; Berk, 2017:521 ve Akgüç, 2013:172).

Tablo 1: Satışlarla ilişkili belirli bilanço kalemleri

\begin{tabular}{|l|l|}
\hline Aktif & Pasif \\
\hline Kisa Vadeli Menkul Değerler & -Kısa Vadeli Ticari Borçlar \\
\hline Kisa Vadeli Ticari Alacaklar & \\
\hline Stoklar & \\
\hline Sabit Varlıklar (Duran Varlıklar) & \\
\hline
\end{tabular}

Kaynak: Bartlomiej Nita. Two Approaches to External Financing Needs Estimation in Financial Planning. Research Papers of Wroclaw University of Economics. Nr.263, 2012, s.137.

Sonraki aşamada, proforma bilanço kalemleri bulunur. Bunun için şu formülden yararlanıldı ̆̆ görülmektedir.

Proforma dönen varlıklar= Tahmini Satışlar x (Mevcut Dönen Varlıklar/Mevcut Dönem Satışları)

Burada proforma dönen varlıklar için yazılan formül satışlarla bağlantılı diğer bilanço kalemleri için de ayrı ayrı uygulanmaktadır.

Bir bilanço kalemi, satışlarla bağlantılı değilse, mevcut dönem tutarıyla proforma bilançoda yer alır. Üçüncü aşamada, yedek akçelerin ne kadar artacağının belirlendiği ifade edilmektedir. Bunun için ilgili formül şu şekilde gösterilebilir:

Yedek akçe artışı= Tahmini satışlar x (Net Kar/Satışlar) x (1-[Nakit kar payı/Net Kar])

Son aşamada da gelecek dönem için kaynak miktarının ne olacağı belirlenmektedir.

Dış kaynak miktarı= Proforma toplam varlıklar-Proforma toplam kaynaklar-Proforma Özsermaye (Keown vd., 2014:465).

Satışların yüzdesi yöntemi uygulama kolaylığı ve maliyet düşüklüğü gibi üstünlükleriyle ön plana çıkmaktadır. Buna karşı, eksik bir yönü vardır. Bu, belirli mali tablo kalemleri ile satışlar arasında geçmişte var olan ilişkinin gelecekte de uygulanmasıdır (Atrill, 2017:73). Bununla birlikte, kısa vadede doğabilecek fon açığının hesaplanmasina uygun bir yöntemdir (Türko, 2002: 153).

\subsubsection{Oranlar Yöntemi}

Üçüncü yöntem ise oranlar yöntemidir. Oran, “mali tablolarda yer alan iki kalem arasındaki ilişkinin basit matematik ifadesi" ya da "bir firmanın finansal bilgilerinden tespit edilen ve karşılaştırma amacıyla kullanılan ilişkiler” şeklinde ifade edilir (Akgüç, 2013:20; Ross vd. 2006: 57).

Oranların ortaya çıkması 20. yüzyılın başlarına rastlamaktadır. Bu dönemde, kredilere yönelik bir çalışmada, cari oranın ve değerinin ele alındığı görülmektedir. Yine aynı dönemde, bankalara yönelik başka bir çalışmada, oranların faydasına vurgu yapıldığı belirtilmektedir. Bu çalışmayla, oranların söz konusu alanlarda süreklilik kazandığı görülebilir (Sarıkamış, 2007: 44).

Oranların birçok faydasının bulunduğu görülmektedir. İlk faydası, hesaplamadaki kolaylıktır. Bu, tanımdan da anlaşılabilir. İkinci faydası, işletmelerin çeşitli açılardan durumunu yansıtmasıdır. Üçüncü faydası ise, faaliyetlerinin büyüklüğü bakımından birbirinden ayrılan işletmelerin finansal bilgilerinin değerlendirilmesine yardımcı olmasıdır. Detaylı incelendiğinde, faaliyet karı ve özsermayesi aynı olmayan firmaların söz konusu kalemleri oranlanarak karşılaştırılabilir hale gelmektedir (Atrill, 2017: 84).

Proforma bilançolar kapsamında, oranlar yönteminin diğer yöntemlerden farklı bir özelliği vardır. Bu çerçevede, yeni faaliyete geçen bir işletme için kullanışlı bir yöntemdir. Söz konusu firmalarda, eski dönemlere ilişkin muhasebe bilgilerinin bulunmaması, bu yöntemden yararlanılmasını zorunlu kılmaktadır. Oranlar yöntemi için iki değişken gereklidir. Bunlar, sektör oranları ile gelecek dönem satışlarıdır (Ceylan ve Korkmaz, 2017:122; Ayrıca bkz ve karş. Ruland ve Zhou, 2004:37).

$\mathrm{Bu}$ avantajlarına rağmen, oranların bazı dezavantajları da vardır. İlk dezavantajı olarak, yorumlamadaki zorluk gösterilebilir (Atrill, 2017:84). İkinci dezavantajı ise muhasebe verileri ile ilgilidir. Bu çerçevede, muhasebe verileri ne kadar doğru ise oranlar da o kadar doğrudur. Üçüncü dezavantajı ise, oranların geçmişi yansıtmasıdır. 
Bu kapsamda, geleceğe dönük analizler için faydalı olmayabileceği vurgulanmaktadır (Fabozzi ve Drake, 2009:8687).

Literatürde, satışların yüzdesi yöntemi ile oranlar yöntemi geleneksel planlama yöntemleri şeklinde ifade edilmektedir (Ersoy, 2017:215, 218).

\subsubsection{Regresyon Yöntemi}

Regresyon yönteminin proforma bilanço oluşturmada alternatif bir seçenek olarak ön plana çıktığ1 görülmektedir. Yöntemin temel özelliği, sadece satışlarla ilişkisi kurulabilen hesapların tutarının belirlenmesidir.

Bu kapsamda, regresyonda bağımsız değişkeni satışların, bağımlı değişkeni ise bilanço kalemlerinin temsil ettiği ifade edilmektedir. Regresyonda, bu iki değişkenin ilişsisinin belirlenebilmesi için geçmişe dönük en az yedi yıllık veriye ihtiyaç duyulmaktadır. Regresyonda, bu iki değişkenin ilişkisi regresyon denklemini meydana getirir. Bilanço hesaplarının gelecekteki değerlerinin belirlenmesinde ise bu regresyon denkleminden faydalanılır (Türko, 2002:153-154; Daha detaylı bilgi için bkz. Ersoy, 2017:221-226).

Satışlar ve bilanço kalemleri ilişkisinin niteliğine göre regresyon denkleminin formülünün farklı biçimlerde yazılabildiği vurgulanmaktadır. Doğrusal bir ilişkide:

$\mathrm{Y}=\mathrm{a}+\mathrm{b} . \mathrm{x}$ formülünden yararlanıldığı gözlemlenmektedir. X satışları, a satışlar sıfırken y değerini, b regresyon katsayısını ve y de ilgili bilanço kalemini temsil ettiği belirtilmektedir. Doğrusal olmayan bir ilişkide de (artan ya da azalan)

$Y=a+b \cdot x+c \cdot x^{2}$ veya $y=a+b \cdot x-c \cdot x^{2}$ formülleri geçerlidir (Berk, 2017:535).

Regresyon yönteminde doğrusal bir ilişki söz konusuyken satı̧̧lar ve örnek bir bilanço kalemi olan alacaklar serpilme grafiğinde aşağıda Şekil 2'deki gibi gözükecektir.

Şekil 2: Regresyon Yöntemi’nde Serpilme Grafiği

Ticari Alacaklar (Bağımlı değișken)

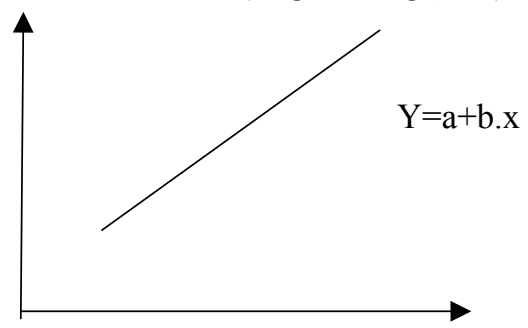

Satışlar (Bağımsız değişken)

Kaynak: Ali Ceylan ve Turhan Korkmaz (2017). İşletmelerde Finansal Yönetim. 15.Baskı. Bursa: Ekin Yayınevi, s.126.

\subsubsection{Günlük Satıșlar Yöntemi}

Günlük satışlar yöntemine göre, proforma bilanço, bilanço hesaplarının günlük satışlar cinsinden ifade edilmesi yardımıyla oluşturulmaktadır. Yöntemin uygulanmasında gerekli değişkenler, gelecek yılın satış tahmini ile bilanço hesaplarının günlük satış cinsinden değerleridir. Gelecek yıl satışlarının günlük değeri ile bilanço hesaplarının günlük satışlar cinsinden değerleri çarpılarak proforma bilanço oluşturulur (Usta, 2014:155). 


\section{UYGULAMA}

Proforma bilançonun hazırlanması ile ilgili yöntemlerden oranlar yöntemi imalat sektöründe yeni kurulacağı varsayılan örnek bir işletmeye uygulanacaktır. Firmanın gelecek yıl için tahmin edilmesi gereken bilanço kalemleri kasa, kısa vadeli ticari alacaklar, stoklar, net maddi duran varlıklar, kısa vadeli borçlar, uzun vadeli borçlar ve özsermayedir (özkaynaklar).

Bu kalemlerin tahmin edilmesi için gerekli veriler imalat sektöründe küçük ölçekli fïmaların verilerinden oluşmaktadır. Bu kapsamda, 2017 yılına ait veriler bulunmadığ için 2016 yılına ait ortalama net satışlar ve standart oranların yardımıyla proforma bilanço oluşturulacaktır. Söz konusu oranlar ve bunların değerleri Tablo 2'de görülebilir.

Tablo 2: İmalat Sektörü Küçük Ölçekli Firmaların Standart Oranları

\begin{tabular}{|l|l|}
\hline Cari Oran & 1,428 \\
\hline Kisa Vadeli Ticari Alacaklar/Dönen Varlıklar & 0,401 \\
\hline Stoklar/Dönen Varlıklar & 0,39 \\
\hline Maddi Duran Varlıklar(Net)/Özkaynaklar & 0,972 \\
\hline Özkaynaklar/Yabancı Kaynak Toplamı & 0,492 \\
\hline Kısa Vadeli Yabancı Kaynaklar/Yabancı Kaynak Toplamı & 0,727 \\
\hline Özkaynaklar Devir Hızı & 3 \\
\hline
\end{tabular}

Kaynak: TCMB. Sektör Bilançoları (2014-2016) http://www3.tcmb.gov.tr/sektor/2017/menu.php

İstatistik Genel Müdürlüğü Reel Sektör Verileri Müdürlüğü; Erişim tarihi: 19.09.2018.

TCMB. Oran Formülleri. http://www3.tcmb.gov.tr/sektor/2017/Raporlar/oran.pdf. Erişim Tarihi: 19.09.2018.

Sektörün 2016 yılına ait ortalama net satışları ise toplam satış tutarının sektördeki firma sayısının toplamına bölünmesiyle bulunabilir. Hesaplamada küçük ölçekli imalat sektörünün Tablo 3'deki Gelir Tablosu kullanılmıştır.

Tablo 3: İmalat Sektörü Küçük Ölçekli Firmaların Gelir Tablolarının Net Satışlar Bölümü

\begin{tabular}{|l|r|}
\hline \multicolumn{1}{|c|}{ (Bin TL) } & $\mathbf{2 0 1 6}$ \\
\hline A-BRÜT SATIŞLAR & $\mathbf{2 2 . 5 9 4 . 1 3 9 , 5}$ \\
\hline 1-Yurt İçi Satışlar & $18.485 .455,2$ \\
\hline 2-Yurt Dişı Satışlar & $3.716 .850,2$ \\
\hline 3-Diğer Gelirler & $391.834,2$ \\
\hline B-SATIŞ İNDİRİMLERİ (-) & $\mathbf{( 6 8 1 . 7 2 6 , 1 )}$ \\
\hline 1-Satıştan İadeler (-) & $(352.150,1)$ \\
\hline 2-Satış İskontoları (-) & $(286.753,7)$ \\
\hline 3-Diğer İndirimler (-) & $(42.822,3)$ \\
\hline C-NET SATIŞLAR & $\mathbf{2 1 . 9 1 2 . 4 1 3 , 4}$ \\
\hline Firma Sayısı & 1.467 \\
\hline
\end{tabular}

Kaynak: TCMB. Sektör Bilançoları (2014-2016) http://www3.tcmb.gov.tr/sektor/2017/menu.php İstatistik Genel Müdürlüğü Reel Sektör Verileri Müdürlüğü Erişim tarihi: 19.09.2018

Ortalama Net Satışlar: 21.912.413.400/1467=14.936.887 TL'dir.

Yeni kurulacağını varsaydığımız örnek işletmenin gelecek yıl 14.936.887 TL'nin biraz üzerinde bir tutar olan 15.000.000 TL'lik net satış yapacağını öngörürsek ilgili işletmenin proforma bilanço kalemleri şu şekilde bulunacaktır:

Özkaynaklar Devir Hızı: 15.000.000/Özsermaye=3 $\rightarrow$ Özsermaye: 15.000.000/3=5.000.000 TL.

Maddi Duran Varlıklar (Net)/5.000.000=0,972 $\rightarrow$ Maddi Duran Varlıklar (Net): 5.000.000 x 0,972= 4.860.000 TL.

5.000.000/Yabanc1 Kaynak Toplamı=0,492 $\rightarrow$ Yabancı Kaynak Toplamı: 5.000.000/0,492=10.162.602 TL. 
Kısa Vadeli Yabancı Kaynaklar/10.162.602 $=0,727 \rightarrow$ Kısa Vadeli Yabancı Kaynaklar: 10.162.602 x $0,727=7.388 .212 \mathrm{TL}$.

Uzun Vadeli Yabancı Kaynaklar: 10.162.602-7.388.212=2.774.390 TL.

Cari Oran: Dönen Varlıklar/7.388.212=1,428 $\rightarrow$ Dönen Varlıklar: 7.388.212 x 1,428=10.550.367 TL.

Kısa Vadeli Ticari Alacaklar/10.550.367=0,401 $\rightarrow$ Kısa Vadeli Ticari Alacaklar: 10.550 .367 x 0,401= 4.230.697 TL.

Stoklar/10.550.367=0,39 $\rightarrow$ Stoklar: 10.550 .367 x 0,39=4.114.643 TL

Kasa: Dönen Varlıklar-(Kısa Vadeli Ticari Alacaklar+Stoklar)

Kasa: $10.550 .367-(4.230 .697+4.114 .643)=2.205 .027 \mathrm{TL}$.

Kaynak ihtiyacı: $15.410 .367-15.162 .602=247.765 \mathrm{TL}$.

Bu sonuçlar kapsamında örnek işletmenin gelecek yıl proforma bilançosu aşağıdaki gibi olacaktır:

Örnek İşletmenin Gelecek Dönem Proforma Bilançosu (TL)

Aktif

Pasif

\begin{tabular}{|l|l|l|l|l|}
\hline & & & $\begin{array}{l}\text { Kisa Vadeli Yabanc1 } \\
\text { Kaynaklar }\end{array}$ & 2 \\
\hline Ticari Alacaklar & 2.205 .027 & & & 7.388 .21 \\
\hline Stoklar & 4.230 .697 & & & \\
\hline & & & & \\
\hline Dönen Varlık Toplamı & 10.550 .367 & & $\begin{array}{l}\text { Uzun Vadeli Yabanc1 } \\
\text { Kaynaklar }\end{array}$ & 0 \\
\hline & & & & 2.774 .39 \\
\hline $\begin{array}{l}\text { Net Maddi Duran } \\
\text { Varlıklar }\end{array}$ & 4.860 .000 & & Özkaynaklar & 5.000 .00 \\
\hline & & & Kaynak İhtiyacı & 5 \\
\hline Toplam Aktifler & 15.410 .367 & & Toplam Pasifler & 67 \\
\hline
\end{tabular}

Görüldüğü gibi proforma bilançoda toplam aktifler toplam pasiflerden büyüktür. Bilançonun dengeye gelebilmesi için (aktif ve pasif eşitliği) işletmenin ilave kaynak bulması gerekmektedir. İlave kaynaklar yabancı kaynaklar ya da özkaynaklardan karşılanabilir. Bu çerçevede, kaynağın maliyetinin ve ödeme koşullarının işletme için kabul edilebilir düzeyde olmasına dikkat edilmelidir (Usta, 2014:155).

\section{SONUÇ}

Ülkemiz koşullarında özellikle pay senedi ihracıyla özkaynak sağlamanın zorluğu ve yabancı kaynak kullanımının daha yaygın olması, örnek işletmenin muhtemel kaynak açığını yabancı kaynakla karşılama olasılığını artırmaktadır. Proforma bilanço geleceğe dönük hazırlanması sebebiyle stratejik bir araçtır. Bu kapsamda, işletmelerin üst yönetimlerinin ilgi alanları arasında yer almaktadır. Üst yönetim işletmeye ne kadar hâkimse hazırlanacak proforma bilançolar da o derece iyi olacaktır. Buna ek olarak, gelecekle ilgili belirsizlik yaratan durumlar/koşullar ne kadar az olursa, söz konusu araç işletme lehine o derece iyi kullanılabilecektir. Tahminlerin dayandığı varsayımların da önceden belirlenmesi bu amaca yardımcı olacaktır. Proforma bilançonun oluşturulması ile ilgili yöntemler proforma bilançoyu kullanan işletmenin özelliğine göre farklılaşmaktadır. Buna karşı, her bir yöntem geleceğe dönük olarak kaynak ihtiyacı/fazlasını belirlediği için değerlidir. Çalışmanın konusuyla ilgili kaynaklar yeterli düzeyde olmakla beraber, bu araştırmanın finansal planlama ve oranlar yöntemi yardımıyla proforma bilanço oluşturma alanında literatüre katkı sağladığı değerlendirilmektedir. 


\section{KAYNAKÇA}

AKGÜÇ, Öztin. (2013). Finansal Yönetim. 8.Bask1. İstanbul:Avcıl Basım.

ATRILL, Peter. (2017). Financial Management for Decision Makers. 8th Edition. Harlow:Pearson Education.

AYDIN, Nurhan, BAŞAR, Mehmet ve COŞKUN, Metin (2010). Finansal Yönetim. 1.Bask1. Ankara: Detay Yayıncılık.

BERK, Niyazi. (2017). Finansal Yönetim. 12.Baskı. İstanbul:Türkmen Kitabevi.

BLOCK, Stanley. B., HIRT, Geoffrey. A ve DANIELSEN, Bartley. R. (2014). Foundations of Financial Management. 15th Edition. USA: McGraw Hill Education.

CEYLAN, Ali. ve KORKMAZ, Turhan. (2017). İşletmelerde Finansal Yönetim. Gözden Geçirilmiş 15. Baskı. Bursa:Ekin Yayınevi.

ERSOY, Hicabi. (2017). Finansal Planlama ve Kontrol. GÜNDOĞDU, Aysel (Ed.). Finansal Yönetim: Temel Teoriler ve Açıklamalı Örnekler içinde, Ankara. Seçkin Yayınevi. 206-234.

FABOZZI, Frank. J. ve DRAKE, Pamela Peterson (2009). Finance: Capital Markets, Financial Management and Investment Management. 1st Edition. New Jersey: John Wiley and Sons.

GÜRSOY, Cudi Tuncer. (2014). Finansal Yönetim İlkeleri. 3. Baskı. İstanbul: Beta Yayınevi.

KEOWN, Arthur. J, MARTIN, John D ve PETTY, J. William (2014). Foundations of Finance:The Logic and Practice of Financial Management. 8th Ed. (Global Ed.). Boston: Pearson Education.

KILIÇ, Uğur Hakan (2012). Kobi Sahipleri ve Finansçı Olmayan Yöneticiler için Finans. Ankara: Sinemis Yayın.

NITA, Bartlomiej. (2012). Two Approaches to External Financing Needs Estimation in Financial Planning. Research Papers of Wroclaw University of Economics. Nr.263, 130-139.

ROSS, Stephen. A., WESTERFIELD, Randolph. W ve JORDAN, Bradford. D. (2006). Corporate Finance Fundamentals. 7th Edition. Boston: McGraw Hill.

RULAND, William ve ZHOU, Ping (2004). Pro Forma Financial Statements for Loan Evaluation. Commercial Lending Review. July, 34-39. $44-45$.

SARIKAMIŞ, Cevat. (2007). Rasyo Analizi Uygulamasının Gelişimi. Muhasebe ve Finansman Dergisi. Sayı 33. Ocak,

TENNENT, John. (2013). Guide to Financial Management. 2nd Edition. The Economist. London: Profile Books.

TÜRKO, Metin.R. (2002). Finansal Yönetim. 2. Baskı. İstanbul. Alfa Yayınları.

USTA, Öcal. (2014). İşletme Finansı ve Finansal Yönetim. 6. Baskı. Ankara: Detay Yayıncılık.

UZUN, Emin., TÜRK, Zehra ve UZUN, Ersen. (2003). İşletme Başarısında Finansal Planlama ve Yeniliklerin Rolü. Yönetim ve Ekonomi. Cilt. 10, Sayı.2, 63-73.

WEYGANDT, Jerry. J., KIMMEL, Paul. D. ve KIESO, Donald. E. (2016). Accounting Principles. 12th Edition. USA: John Wiley and Sons.

\section{İnternet Kaynakları}

Business Forecasting. Planning for a Rainy Day. https:/www.dummies.com/business/start-a-business/businessplans/business-forecasting-planning-for-a-rainy-day/ Erişim Tarihi: 05.06. 2018.

TCMB. Sektör Bilançoları (2014-2016) http://www3.tcmb.gov.tr/sektor/2017/menu.php İstatistik Genel Müdürlüğü Reel Sektör Verileri Müdürlüğü Erişim tarihi: 19.09.2018

TCMB. Oran Formülleri. http://www3.tcmb.gov.tr/sektor/2017/Raporlar/oran.pdf. Erişim Tarihi: 19.09.2018 